\title{
Cantares do exílio: dois poemas de Lhasang Tsering
}

Francesca Cricelli

\begin{abstract}
Resumo: Este artigo é uma tradução comentada de dois poemas do poeta exilado tibetano, e ex-guerrilheiro, Lhasang Tsering. No texto discute-se também como esses poemas de Lhasang retratam a condição inescapável do exílio e as dificuldades dos refugiados, que de alguma forma se assemelha à injustiça social no Brasil e em outros cantos, ainda que seja muito distinto do exílio vivido pela comunidade tibetana desterritorializada.
\end{abstract}

Palavras-chave: Lhasang Tsering; exílio; poesia; resistência

\begin{abstract}
This article is an annotated translation of two poems of Tibetan exile poet and former guerilla fighter Lhasang Tsering. I also discuss how these two poems of Lhasang depict the inescapable condition of exile and the struggles of displaced refugees, which at once bear some semblance to social injustices in Brazil and elsewhere and yet are very distinct to the exile experience of the de-territorialized Tibetan community.
\end{abstract}

Keywords: Lhasang Tsering; exile; poetry; resistance 


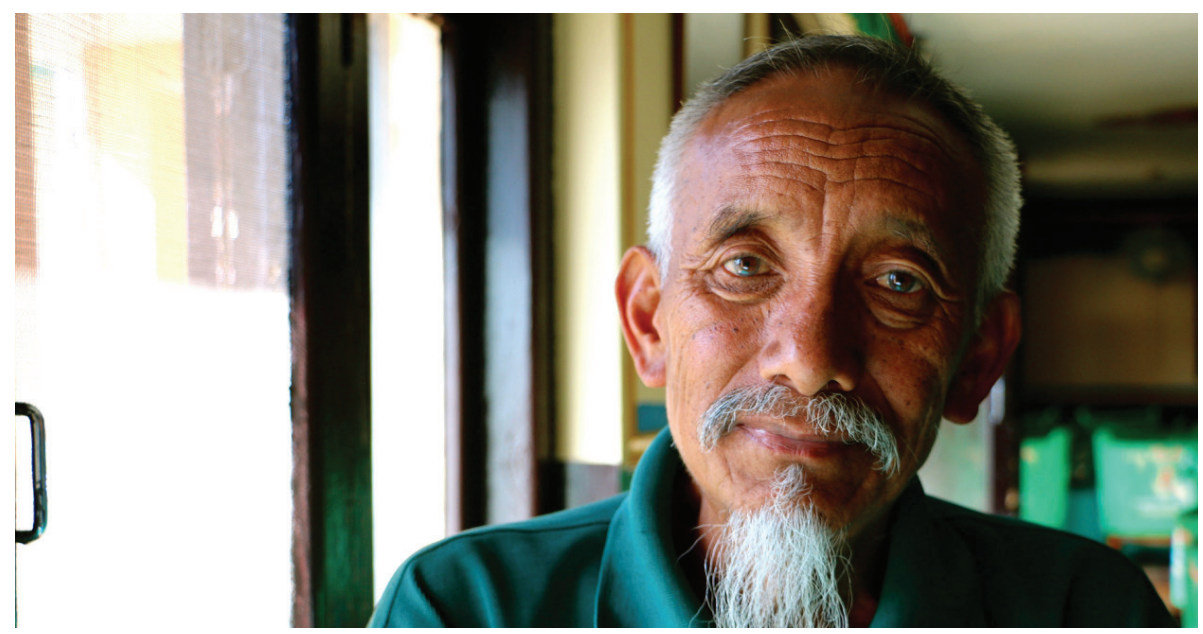

Lhasang Tsering (1952-) é poeta, escritor e ativista. Nasceu no Tibete, provavelmente ao redor da região do monte sagrado Kailash. Deixou o país em 1958 com sua família e exilou-se na região de Dharamsala, na Índia. Lhasang Tsering fez parte da resistência armada tibetana, além haver presidido o Congresso da Juventude Tibetana e dirigido a Escola de Tibetanos em Situação de Refúgio, na Índia. Em sua trajetória, é interessante observar como, ao ter a oportunidade de deixar o território do seu país em exílio e estudar medicina nos EUA, Lhasang Tsering optou por aderir à luta armada. Numa entrevista concedida à Universidade de Arkansas, ${ }^{1}$ o poeta e ativista relata como tanto o treinamento quanto os arsenais usados nesse processo eram estadunidenses, e os materiais eram lançados em voo sobre o território ocupado pelos exilados na Índia. Seu relato é muito tocante, pois revela a complexidade desse conflito político, sendo uma das questões apontadas pelo poeta e ativista o fato de o contingente de guerrilheiros, num certo momento, haver começado a entrar em conflito interno e, aos poucos, o movimento foi se dissolvendo. Lhasang Tsering também é um dos fundadores e diretores do Instituto Amnye Machen (Instituto Tibetano de Estudos Avançados), sediado em Dharamsala. Publicou três livros de poemas - Tomorrow and Other Poems (2004),

1 University of Arkansas TEXT students were granted an interview with Lhasang Tsering. https:// www.youtube.com/watch?v=LPat-pDPKgY (consultado em setembro de 2020). 
Ocean of Melody -, uma tradução dos Cantares do Sexto Dalai Lama (2009) e Hold On and other Verses (2010). Também foi proprietário de uma livraria em Dharamsala. Apresentamos aqui a tradução de dois poemas: "8 X 10" e "Nascido no Exílio".

\section{$8 \times 10$}

Oito por dez

Em qualquer unidade

Grande ou pequena

É um retângulo.

Oito por dez

Com quatro paredes

Um teto

É um cômodo.

Oito por dez

Medido em pés

Em qualquer país

É um cômodo pequeno.

Oito por dez

Para um refugiado

É com frequência

O único cômodo.

Oito por dez

Com uma cama

E um fogão

Não é só um cômodo.

Oito por dez

Com uma mãe

E um altar

É um lar.

Com nascimento e morte

Júbilo e lágrimas 
Como uma casa

Em qualquer lugar.

Um canto para dividir

Um canto para amar

Ainda que só

Oito por dez.

\section{8 by 10}

Eight by ten

In any unit

Big or small

Is a rectangle.

Eight by ten

With four walls

And a roof

Is a room.

Eight by ten

Measured in feet

In any country

Is a small room.

Eight by ten

For a refugee

Is quite often

The only room.

Eight by ten

With a bed

And a stove

Is not just a room. 
Eight by ten

With a mother

And an alter

Is a home.

With birth and death

Joy and tears

Like any home

Anywhere.

A place to share

A place to Love

Though only

Eight by ten.

\section{Nascido no exílio}

Nascido forasteiro em exílio, sinto-me

Uma pipa solta em pleno ar,

Um barco sem velas e à deriva,

Uma semente plantada em solo pedregoso,

Um pardal sobre um oceano.

Nascido numa terra estrangeira, sinto-me

Uma flor caída no esquecimento

Um pássaro sem asas,

Um peixe retirado do rio

Um cordeiro perdido no deserto.

Nascido um refugiado sem país, sou

Uma criança sem um canto para chamar de casa,

Uma mulher sem nome,

Um homem sem nacionalidade,

Um ser humano sem direitos. 
Nascido sem direitos, sou

Um desamparado, traído pela esperança,

Um prece que não foi ouvida nem respondida,

Uma promessa rompida, descumprida.

Um sonho vazio, estilhaçado.

\section{Born in Exile}

Born an alien in exile, I feel like -

A kite cut loose in mid-air,

A boat adrift without sails,

A seed sown on rocky soil,

A sparrow over an ocean.

Born in a foreign land, I feel like -

A flower fallen by the wayside

A bird without wings,

A fish thrown out of the river

A lamb lost in a trackless desert.

Born a stateless refugee, I am -

A child with no place to call home,

A woman with no name,

A man with no nationality,

A human with no rights.

Born without any rights, I am -

A forlorn, betrayed hope,

An unheard, unanswered prayer,

A broken, unfulfilled promise,

An empty, shattered dream. 


\section{Cantares do exílio}

Não é possível falar de "canção" e de "exílio" em linha reta sem ouvir na própria mente os versos emblemáticos do nosso romantismo e com ele todas as suas reverberações. Entre paródias e intertextualidades, relembramos aos pouco também os versos de Oswald de Andrade: "Não permita Deus que eu morra / Sem que volte para São Paulo", ou de Murilo Mendes: "Os poetas da minha terra/ são pretos que vivem em torres de ametista,/ os sargentos do exército são monistas, cubistas, / os filósofos são polacos vendendo a prestações/" ou de Carlos Drummond de Andrade: "Ainda um grito de vida e/voltar/ para onde tudo é belo/ e fantástico:/ a palmeira, o sabiá,/ o longe". Mas o cantar de exílio que abordamos aqui é de outra ordem e natureza. Não se trata de narrar a nostalgia, nem mesmo de repensá-la no tempo. O exílio aqui é uma condição inescapável, talvez mais próxima dos versos do nosso poeta Thiago de Mello: "Faz escuro, mas eu canto".

No poema " 8 x 10", Lhasang Tsering relata em versos os primeiros anos da sua vida em exílio. A história do conflito sino-tibetano é longa e permeada por diversas ondas de embate. A ocupação atual, por parte da China, teve seu início em 1950. A familia de Lhasang Tsering migrou para a Índia, atravessando a cordilheira com seus poucos pertences, nas costas de um iaque, em 1958. Segundo o poeta:

Esse poema foi escrito para preservar a memória de um pequeno cômodo sob o Templo tibetano no Vale da Felicidade em Mussoorie, na Índia, onde até o final de 1960 minha mãe passou os últimos anos da vida dela e era um "lar" para mim e meus dois irmãos, meu padrasto e duas crianças, nossos meios irmãos. ${ }^{2}$

O exílio de Lhsang Tsering não é temporário. É atemporal e incontornável. Mesmo chegando muito novo à Índia, sua condição permanece a de um forasteiro nascido em exílio, descreve-a numa série de enumerações no poema "Nascido no Exílio". Há objetos que flutuam e existem soltos, como se não tivessem passado nem futuro, como se não houvesse de onde partir e aonde chegar: "uma pipa solta no ar", "um barco sem velas à deriva", enfim, "uma semente" que precisa encontrar uma forma de vingar num "solo pedregoso". Esse solo inóspito poderia ser também “Oito por dez/ Medido em pés/ Em qualquer país/ É um cômodo

2 Lhasang Tsering. Muse India Journal. Guest edition on Tibetan Writing in India. Eds Shelly Bhoil and Tsering Shakya. https://museindia.com/Home/ViewContentData? arttype=feature\&issid $=57 \& \mathrm{menu}$ $\mathrm{id}=5145$ 
pequeno" - esse núcleo-casa, essa casa-cômodo onde viveram todos juntos por anos, pois "Oito por dez/ Para um refugiado/ É com frequência/ O único cômodo”. Com toda especificidade histórica e política que atravessa a ocupação do território tibetano - a história do poeta e ativista, o governo em exílio - podemos reconhecer em seus versos uma condição humana tão próxima ao nosso país, onde muitos são exilados em sua própria terra. Também nas periferias do Brasil, em nosso país, onde vige um sistema de exclusão, injustiça social e racismo estrutural, se caminha como se nascidos sem direitos: "Um desamparado, traído pela esperança, /Uma prece que não foi ouvida nem respondida, /Uma promessa rompida, descumprida. /Um sonho vazio, estilhaçado". Criamos uma ponte humana em nossa leitura e tradução, servimos de escuta para o que está distante e também sob nossos olhos. Lhsang Tsering relata que o mesmo tipo de cômodo pequeno foi sua casa, anos adiante, já casado, quando era presidente do Congresso de Jovens Tibetanos (1986-1990) ou participava do Instituto Amney Machen (1992-1999): “(...) foi um cômodo semelhante em que morei no Tibetan Handicraft Center em McLeod Ganj que era nosso 'lar' para mim, para minha esposa e duas crianças". ${ }^{3}$ Mas há o tecido humano que luta e resiste, a vida que insiste, portanto "Oito por dez /Com uma mãe/ e um altar/É uma lar./ / Com nascimento e morte/ Júbilo e lágrimas / Como uma casa / Em qualquer lugar". Só a preservação da memória, da cultura e da língua, animados pela luta política, podem fazer com que "Um peixe" não seja "retirado rio" ou que "Um cordeiro" não ande "perdido no deserto". Perder a língua também é uma ferida, e o poeta Lhsang Tsering comenta em sua entrevista à Universidade de Arkansas ${ }^{4}$ que perdeu um pouco da sua habilidade com a língua materna ao ser selecionado, ainda muito novo, para estudar numa escola fundada por missionários na região onde só os melhores alunos poderiam estar, mas diz que isso lhe deu a possibilidade de se comunicar bem em inglês e levar, dessa forma, seu país exilado para outros cantos do mundo. Entre as perdas inevitáveis e evitáveis, lutar e preservar um núcleo, um oito por dez dentro de si, "Um canto" para dizer e "para dividir".

3 Lhasang Tsering. Muse India Journal. Guest edition on Tibetan Writing in India. Eds Shelly Bhoil and Tsering Shakya. https://museindia.com/Home/ViewContentData?arttype=feature\&issid=57\&menu $\underline{\mathrm{id}}=5145$

4 University of Arkansas TEXT students were granted an interview with Lhasang Tsering. https:// www.youtube.com/watch? $\mathrm{v}=\mathrm{LPat}-\mathrm{pDPKgY}$ (consultada em setembro de 2020) 


\section{Referências bibliográficas}

ANDRADE, Carlos Drummond. (2003). Poesia Completa. Rio de Janeiro: Nova Aguilar. ANDRADE, Oswald. (1925). Pau-Brasil. Paris: Au Sans Pareil.

DE MELLO, Thiago. (2017). Faz escuro mas eu canto. Global Editora: São Paulo.

LHASANG, Tsering. Muse India Journal. Guest edition on Tibetan Writing in India. Eds Shelly Bhoil and Tsering Shakya. https://museindia.com/Home/ViewContentData?artt ype $=$ feature\&issid $=57 \&$ menuid $=5145$

. University of Arkansas TEXT students were granted an interview with Lhasang Tsering. https://www.youtube.com/watch?v=LPat-pDPKgY (consultada em setembro de 2020)

MENDES, Murilo. Poesias, 1925/1955. Rio de Janeiro: J. Olympio, 1959.

Francesca Cricelli é doutora em Literaturas Estrangeiras e Tradução (LETRA) pela Universidade de São Paulo. É tradutora literária, tendo já traduzido, entre outras, Elena Ferrante e Igiaba Scego, e poeta, tendo publicado Repátria (Selo Demônio Negro, 2015), 16 poemas +1 (Sagarana forlag, 2017), As curvas negras da terra (Nosotros Editorial, 2019) e o livro de viagens Errância (Macondo Edições, 2019). Mora atualmente em Reykjavík, onde estuda língua e literatura islandesa. 